\title{
Upregulation of bfl-I is a potential mechanism of chemoresistance in B-cell chronic lymphocytic leukaemia
}

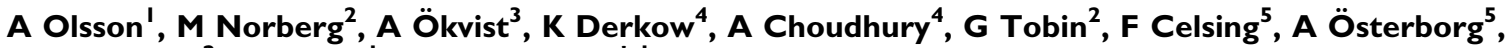 R Rosenquist ${ }^{2}$, M Jondal' and LM Osorio*,I}

'Department of Tumor and Cell Biology, Karolinska Institutet, Stockholm 17177, Sweden; ${ }^{2}$ Department of Genetics and Pathology, Rudbeck Laboratory, Uppsala University, Uppsala 75185, Sweden; ${ }^{3}$ Department of Clinical Neuroscience, Karolinska University Hospital, Stockholm 17176, Sweden; ${ }^{4}$ Department of Oncology-Pathology, Karolinska Institutet, Stockholm 17I 77, Sweden; ${ }^{5}$ Departments of Hematology and Oncology, Karolinska University Hospital, Stockholm 17176, Sweden

B-cell chronic lymphocytic leukaemia (B-CLL) is characterised by the progressive accumulation of monoclonal CD5 ${ }^{+} \mathrm{B}$ cells. In a previous study, we have analysed the expression profile of apoptosis-regulating genes using a cDNA-based microarray and found overexpression of the antiapoptotic bcl-2 family member, bfl-I, in B-CLL cells with an apoptosis-resistant phenotype. In this study, bfl- I mRNA levels have been determined by competitive PCR in an extended population of B-CLL patients to characterise its role in disease progression and development of chemoresistance. bfl- I levels were significantly higher in patients with no response (NR) to last chemotherapy than in patients responding (partial response $(P R))$ to last chemotherapy $(P<0.05)$ and in patients who had not required treatment $(P<0.05)$. We found no correlation between bfl-I mRNA levels and disease progression, IGHV mutational status or other clinical parameters. In addition, bfl-I mRNA levels were inversely correlated with apoptotic response to in vitro fludarabine treatment of B-CLL cells. Specific downregulation of bfl- I using siRNA induced apoptosis in resistant cells. Our data suggest that bfl- I contributes to chemoresistance and might be a therapeutic target in B-CLL.

British Journal of Cancer (2007) 97, 769-777. doi: I0.1038/sj.bjc.660395 I www.bjcancer.com

Published online 28 August 2007

(c) 2007 Cancer Research UK

Keywords: Bfl- I; B-CLL; apoptosis; chemoresistance

B-cell chronic lymphocytic leukaemia (B-CLL) is characterised by the accumulation of a clonal population of malignant $\mathrm{CD} 5^{+} \mathrm{B}$ cells in the blood, bone marrow, lymph nodes and spleen (Jurlander, 1997). Patients with B-CLL follow a highly variable clinical course. Some patients remain stable for a long time, without the need for therapy, while others progress rapidly to a more advanced disease and die despite aggressive treatment (O'Brien et al, 1995). Although this disease is still incurable, responses are observed with alkylating agents or nucleoside analogues. However, despite initial responses to therapy, relapse and eventual chemotherapy resistance usually occur in B-CLL patients.

B-CLL cells have a low proliferative rate and a prolonged life span, suggesting that their accumulation in vivo results from defects in the apoptotic process (Hamblin and Oscier, 1997). The underlying defects in apoptosis in B-CLL cells also contribute to chemotherapy resistance. The mechanisms behind the resistance of B-CLL to apoptosis are largely still undefined, but previous studies support a regulatory role of Bcl-2 family of apoptosisregulatory proteins, such as $\mathrm{Bcl}-2 / \mathrm{Bax}$ and $\mathrm{Mcl}-1$, in the survival of B-CLL cells (Aguilar-Santelises et al, 1996; Osorio et al, 1997; Kitada et al, 1998; Morales et al, 2005).

*Correspondence: Dr LM Osorio; E-mail: lyda.osorio@ki.se Received 21 May 2007; revised 31 July 2007; accepted I August 2007; published online 28 August 2007
Bfl-1 is an antiapoptotic member of the Bcl-2 family shown to protect from apoptosis induced by a variety of apoptotic stimuli such as death-receptor ligation (Werner et al, 2002), p53 overexpression (D'Sa-Eipper et al, 1996), DNA-damaging agents (Wang et al, 1999) and serum deprivation (Zhang et al, 2000). Recently, it was reported that Bfl-1 can also promote apoptosis after TNF receptor activation in pro-B cells, dependent on proteolytic processing of Bfl-1 (Kucharczak et al, 2005). This work suggests that Bfl-1 may exert different effects depending on the nature of the death-inducing stimulus. In humans, bfl-1 expression is found in various types of haematopoietic cells in the bone marrow, in germinal centres of peripheral lymphoid organs, haematopoietic cells of fetal liver (Jung-Ha et al, 1998), endothelial cells and in smooth muscle cells (Karsan et al, 1996). bfl-1 is a direct transcriptional target of NF- $\kappa \mathrm{B}$ (Zong et al, 1999), and is inducible by inflammatory stimuli in various cell types (Karsan et al, 1996; Moreb and Schweder et al, 1997). In B lymphocyte-derived cell lines and in primary B cells bfl-1 is induced by CD40 ligation and has been shown to protect from apoptosis triggered by ligation of the Bcell receptor or Fas (Kuss et al, 1999; Craxton et al, 2000). In B-CLL bfl-1 is inducible by B-cell receptor crosslinking and CD40L (Bernal et al, 2001; Kater et al, 2004). bfl-1 has also been implicated in CD40L mediated resistance towards fludarabine-induced apoptosis in B-CLL cells (Kater et al, 2004). Inhibition of constitutive and inducible NF- $\kappa \mathrm{B}$ using NF- $\kappa \mathrm{B}$ inhibitors induced apoptosis and enhances fludarabine effects on B-CLL associated with downregulation of bfl-1 and other antiapoptotic genes (Horie et al, 2006). 
In a previous study, using a cDNA-based microarray approach to characterise expression of apoptosis-regulating genes in B-CLL, we found the antiapoptotic bcl-2 family member bfl-1 as the most discriminating gene between untreated patients whose leukaemic cells were sensitive to in vitro fludarabine-induced apoptosis and chemotherapy refractory patients with in vitro fludarabine-resistant leukaemic cells (Morales et al, 2005). In the present study, bfl-1 mRNA levels have been quantified by competitive PCR in an extended population of B-CLL patients to characterise its role in disease progression and development of chemoresistance. We show a correlation between high bfl-1 expression and chemotherapy refractoriness and resistant to in vitro fludarbine-induced apoptosis. In addition, by siRNA-mediated targeting we demonstrate that downmodulation of bfl-1 induces apoptosis in resistant B-CLL cells.

\section{MATERIALS AND METHODS}

\section{Reagents}

Primers for PCR amplification were synthesised by CyberGene AB (Huddinge, Sweden). Trizol Reagent, oligo $(\mathrm{dT})_{15}$ primer and MMLV reverse transcriptase were from Invitrogen (Carlsbad, CA, USA). Fluorescein isothiocyanate (FITC)-F( $\left.a b^{\prime}\right) 2$ fragment of rabbit anti-human IgM, phycoerythrin (PE)-conjugated anti-CD25, anti-CD3-PE, anti-CD5-FITC and anti-CD20-PE were from Dakocytomation A/S (Copenhagen, Denmark). Anti-CD38-PE, allophycocyanin (APC) conjugated anti-CD19 and IgG1-FITC/IgG2a-PE simultest were from Becton Dickinson (Mountain View, CA, USA). Fludarabine and chlorambucil were from Sigma Chemicals (St Louis, MO, USA).

\section{Patients}

The study was approved by the Karolinska Institutet Ethics Committee and informed consent was obtained from all patients. No antitumor therapy was allowed for at least 1 month prior to sample acquisition. All patients had a confirmed diagnosis of B-CLL and were staged according to Rai et al (1975). Patients were considered to have a progressive disease, according to a modification of the criteria by the National Cancer Institute Committee (Silver et al, 1978), if there was progression during the preceding 3 months in disease-related anaemia (and $\mathrm{Hb}$ $<100 \mathrm{gl}^{-1}$ ), in thrombocytopaenia (and platelet count $<100 \times 10^{9} 1^{-1}$ ) and/or in spleen/liver/lymph node size (evaluated by both clinical examination and computer tomography of the abdomen) and/or in more than a doubling of the blood lymphocyte counts and/or appearance of constitutional symptoms. Response to chemotherapy treatment was classified as no response, partial response or complete response (NR, PR or CR) according to the NCI-WG criteria (Cheson et al, 1996); (Table 1).

\section{Cell separation}

Leukaemic B cells were isolated from heparinised blood taken from B-CLL patients. Lymphocytes were obtained after carbonyl iron treatment and Lymphoprep (Nycomed, Oslo, Norway) centrifugation, and $\mathrm{T}$ cells were depleted by rosetting with sheep erythrocytes. Isolated cells were kept frozen in aliquots. Isolated non-rosetting, leukaemic B cells contained less than $2.0 \% \mathrm{CD}^{+}$ cells as estimated by flow cytometry.

\section{Cell phenotype}

Isolated cells from all B-CLL patients were phenotyped by immunofluorescence and flow cytometry. Cells $\left(1 \times 10^{6}\right)$ were incubated for $30 \mathrm{~min}$ at $4^{\circ} \mathrm{C}$ with anti-CD5-FITC, anti-CD19-APC, anti-CD25-PE, anti-CD20-PE, anti-CD38-PE, anti-CD3-PE or FITC$\mathrm{F}\left(\mathrm{ab}^{\prime}\right) 2$ anti-human IgM. FITC/PE-conjugated simultest was used as control. Forward and side-scatter gates were set to exclude dead cells. All samples were analysed in a Becton Dickinson FACScan system equipped with an argon laser, using 10000 cells for each determination.

\section{Cell cultures}

B-CLL cells were re-suspended in RPMI-1640 medium supplemented with $2 \mathrm{~mm}$ glutamine, $100 \mathrm{IU} \mathrm{ml}^{-1}$ penicillin, $100 \mu \mathrm{g} \mathrm{ml}^{-1}$ streptomycin and $0.5 \%$ bovine serum albumin (BSA fraction-V). Cells $\left(0.5 \times 10^{6} \mathrm{ml}^{-1}\right)$ were incubated in 96 -well plates in medium alone (spontaneous apoptosis) or in the presence of fludarabine $(5 \mu \mathrm{M})$ or chlorambucil $(40 \mu \mathrm{M})$ for $48 \mathrm{~h}$ to evaluate apoptotic response. The NIH3T3 mouse fibroblast cell line transfected with human CD40L were cultured in RPMI-1640 medium supplemented with $10 \%$ fetal bovine serum (FBS), $2 \mathrm{~mm}$ glutamine, $100 \mathrm{IU} \mathrm{ml}^{-1}$ penicillin, $100 \mu \mathrm{g} \mathrm{ml}^{-1}$ streptomycin in 24 -well plates $\left(2 \times 10^{5}\right.$ cells per well), and incubated overnight to adhere before addition of siRNA-transfected B-CLL cells.

\section{Apoptosis}

Percentage of apoptotic cells was determined by AnnexinV staining. Cells were washed with PBS and incubated $10 \mathrm{~min}$ in $100 \mu \mathrm{l}$ of binding buffer (10 mM HEPES/NaOH, pH 7.4, $140 \mathrm{~mm}$ $\mathrm{NaCl}, 5 \mathrm{~mm} \mathrm{CaCl}{ }_{2}$ ) containing AnnexinV-Fluos solution (Roche Molecular Biochemicals, Mannheim, Germany) and $2 \mu \mathrm{g} \mathrm{ml}^{-1}$ propidium iodide (Sigma Chemicals). Cells were analysed with a FACScan (Becton Dickinson). For fludarabine- and chlorambucilinduced apoptosis percentages of specific apoptosis were calculated as (apoptosis in drug culture-spontaneous apoptosis)/ $(100-$ spontaneous apoptosis $) \times 100 \%$.

\section{Competitive PCR}

Total RNA was isolated from purified B-CLL cells using Trizol reagent. Three micrograms of total RNA was denatured and reverse transcribed using oligo- $(\mathrm{dT})_{15}$ primers. Thereafter, $1 \mu \mathrm{l}$ of cDNA was amplified in a $20 \mu \mathrm{l}$ PCR mixture. Two microlitres of serial dilutions of competitor fragments, with different lengths but using the same primers as the target DNA, was added to the reaction. G3PDH competitor (MIMIC, $630 \mathrm{bp}$ ) was from Clontech (Mountain View, CA, USA) and the $b f l-1$ competitor (446 bp) was from Gentaur Molecular Products (Brussels, Belgium). Competitor for bcl-2 (230 bp) was built using composite primers and an exogenous DNA fragment (BamHI-EcoRI restriction fragment from $v$-erb). Cycling conditions for bfl-1 and bcl-2 were 30 cycles of $1 \mathrm{~min}$ at $94^{\circ} \mathrm{C}, 1 \mathrm{~min}$ at $60^{\circ} \mathrm{C}$ and $2 \mathrm{~min}$ at $72^{\circ} \mathrm{C}$ and for G3PDH 35 cycles of $1 \mathrm{~min}$ at $94^{\circ} \mathrm{C}, 1 \mathrm{~min}$ at $60^{\circ} \mathrm{C}$, and $1 \mathrm{~min}$ at $72^{\circ} \mathrm{C}$. The samples were then resolved on a $2 \%$ agarose gel with $1 \mu \mathrm{g} \mathrm{ml}^{-1}$ of ethidium bromide and photographed. Densitometric analysis was performed using Quantity One (BioRad, Hercules, CA, USA). Ratios of the intensity of the relevant PCR product pairs were plotted against the concentration of the competitor DNA used in a logarithmic plot. The point of intersection in the curve, where the amounts of target and competitor are equal was used to determine the amount of cDNA in the sample. The primers are as follows: sense $b f l-1,5^{\prime}$-GGCAGAAGATGACAGACTGTGAA-3'; antisense bfl-1, 5'-TGGTCAACAGTATTGCTTCAGGA-3' (539 bp); sense $b c l$-2, 5'-CGACGACTTCTCCCGCCGCTACCGC-3'; antisense $b c l-2$, $5^{\prime}$-CCGCATGCTGGGGCCGTACAGTTCC-3' (319bp); sense G3PDH, 5'-TGAAGGTCGGAGTCAACGGATTTGGT- $3^{\prime}$; antisense G3PDH, 5'-CATGTGGGCCATGAGGTCCACCAC-3' (983 bp).

\section{siRNA treatment of B-CLL cells}

Transfection of B-CLL cells was performed according to a modified and optimised TransIT-TKO ${ }^{\mathbb{R}}$ Transfection Reagent (Mirius 
Table I Clinical characteristics, apoptotic response, mutational status and genetic alterations of included patients

\begin{tabular}{|c|c|c|c|c|c|c|c|c|c|c|c|}
\hline CLL & $\begin{array}{l}\text { Sexl } \\
\text { age }\end{array}$ & $\begin{array}{l}\text { Rai } \\
\text { stage }\end{array}$ & Progression & $\begin{array}{l}\text { Mo since } \\
\text { diagnosis }\end{array}$ & $\begin{array}{l}\text { Previous } \\
\text { therapy }^{\text {a }}\end{array}$ & $\begin{array}{l}\text { Blood lymphocyte count } \\
\qquad\left(\times 10^{9} I^{-1}\right)\end{array}$ & $\begin{array}{l}\text { Fludarabine-specific } \\
\text { apoptosis (\%) }\end{array}$ & $\begin{array}{l}\text { CLB-specific } \\
\text { apoptosis (\%) }\end{array}$ & $\begin{array}{c}\text { Response to } \\
\text { therapy }\end{array}$ & FISH code $^{b}$ & $\begin{array}{l}\text { IGHV mutational status }{ }^{c} \\
\text { IGHV3-2 I }\end{array}$ \\
\hline 1 & $M / 73$ & 0 & - & 53 & - & 40 & 24.0 & 59.1 & - & $\operatorname{del}(\mid 3 q)$ & Mutated (high) \\
\hline 2 & $M / 66$ & 0 & - & 68 & - & 20 & 90.4 & 98.4 & - & ND & Mutated (high) \\
\hline 3 & $F / 61$ & 0 & - & 135 & - & 78 & 82.0 & 84.6 & - & $\operatorname{del}(\mid 3 q)$ & Mutated (high, NF) \\
\hline 4 & $M / 67$ & 0 & - & 90 & - & 22 & 88.1 & 94.9 & - & Normal & ND \\
\hline 5 & $M / 86$ & 0 & - & 39 & - & 55 & 80.4 & 26.4 & - & $\operatorname{del}(|| q)$ & Mutated (high) \\
\hline 6 & $F / 76$ & 0 & - & 47 & - & 62 & 75.7 & 59.4 & - & Normal & Mutated (high) \\
\hline 7 & $F / 81$ & 0 & - & 179 & - & 104 & 89.0 & 89.1 & - & trisomy 12 & Mutated (low) \\
\hline 8 & $M / 69$ & 0 & - & 78 & - & 25 & 82.6 & 45.8 & - & $\operatorname{del}(\mid 3 q)$ & Mutated (low) \\
\hline 9 & $M / 69$ & 0 & - & 26 & - & 74 & 42.5 & 67.6 & - & ND & Unmutated \\
\hline 10 & $M / 58$ & 0 & - & 30 & - & 35 & 88.4 & ND & - & ND & Mutated (high) \\
\hline 11 & $M / 59$ & 0 & - & 76 & - & 27 & 13.4 & 18.7 & - & $\operatorname{del}(\mid 3 q)$ & Mutated (high, NF) \\
\hline 12 & $M / 76$ & 0 & - & 32 & - & 147 & 71.5 & 78.3 & - & $\operatorname{del}(|| q)$ & Mutated (high) \\
\hline 13 & $M / 71$ & I & - & 10 & - & 30 & 79.8 & ND & - & ND & Unmutated \\
\hline 14 & $\mathrm{~F} / 70$ & I & - & & - & 112 & 73.6 & 72.4 & - & $\operatorname{del}(\mid 3 q)$ & Mutated (low) \\
\hline 15 & $F / 73$ & i & - & 77 & - & 27 & 85.1 & 96.3 & - & ND & Mutated (high, NF) \\
\hline 16 & $M / 68$ & i & - & 5 & - & 42 & 76.9 & 39.1 & - & $\operatorname{del}(|| q)$ & Unmutated \\
\hline 17 & $M / 66$ & $\|$ & - & 72 & - & 41 & 71.2 & ND & - & ND & Mutated (high) \\
\hline 18 & $\mathrm{~F} / 79$ & $\|$ & - & 68 & $\mathrm{CLB}(9)$ & 48 & 44.9 & 79.4 & NR & $\operatorname{del}(13 q)$ & Mutated (high) \\
\hline 19 & $M / 85$ & III & - & 150 & CLB (13) & 138 & 68.5 & 55.9 & $P R$ & $\operatorname{del}(|| q)$ & Mutated (low) \\
\hline 20 & $\mathrm{~F} / 77$ & 0 & + & 122 & $\mathrm{CLB}(6)$ & 38 & 65.3 & 50.9 & PR & trisomy 12 & Mutated (low) IGHV3-2I \\
\hline 21 & $F / 79$ & । & + & 53 & $\mathrm{CLB}(6)$ & 61 & 69.0 & 81.2 & PR & $\operatorname{del}(\mid 3 q)$ & Mutated (low) \\
\hline 22 & F/69 & $\|$ & + & 58 & $\mathrm{CLB}(\mathrm{I})$ & 54 & 7.4 & ND & $N R$ & $\operatorname{del}(13 q)$ & Mutated (low) \\
\hline 23 & $M / 86$ & $\|$ & + & 29 & CLB (5) & 117 & 82.8 & 55.7 & $P R$ & $\operatorname{del}(\mid 3 q)$ & Unmutated IGHV3-2I \\
\hline 24 & $M / 65$ & $\|$ & + & 29 & CLB (I) & 329 & 21.8 & -5.5 & NR & Normal & Mutated (low) \\
\hline 25 & $M / 70$ & $\|$ & + & 96 & CLB (72) & 66 & 11.7 & 13.8 & $N R$ & $\begin{array}{l}\text { del( }(17 p)- \\
\text { borderline }\end{array}$ & Unmutated \\
\hline 26 & $M / 61$ & $\|$ & + & 61 & FLUD (38) & 53 & 40.6 & 32.4 & PR & $\operatorname{del}(17 p)$ & Mutated (high) \\
\hline 27 & $F / 87$ & $\|$ & + & 260 & $\operatorname{COP}(12)$ & 176 & 18.6 & -1.3 & NR & Inconclusive & Mutated (high, NF) IGHV3-2I \\
\hline 28 & $F / 80$ & $\|$ & + & 69 & CLB (8) & 208 & 85.8 & 18.0 & PR & trisomy 12 & Mutated (high) \\
\hline 29 & $M / 81$ & $\|$ & + & 24 & CLB (5) & 200 & 66.4 & 19.7 & PR & $\begin{array}{l}\operatorname{del}(|| \mathrm{q})(\& \\
\text { trisomy |2) }\end{array}$ & Mutated (low) IGHV3-2I \\
\hline 30 & $M / 64$ & III & + & 23 & FLUD (II) & 354 & 32.3 & -2.5 & NR & $\operatorname{del}(13 q)$ & Mutated (low, NF) \\
\hline 31 & $M / 67$ & III & + & 142 & MIME (7) & 304 & 3.5 & 7.1 & NR & $\operatorname{del}(17 p)$ & Unmutated \\
\hline 32 & $F / 69$ & III & + & 239 & FLUD (II) & 198 & 7.9 & 5.3 & NR & $\operatorname{del}(\mid 3 q)$ & Mutated (high) \\
\hline 33 & $\mathrm{~F} / 80$ & III & + & 216 & CLB (I) & 176 & 16.4 & 26.3 & NR & ND & Unmutated \\
\hline 34 & $F / 52$ & IV & + & 116 & CLB (19) & 69 & 92.5 & 96.9 & NR & trisomy 12 & Mutated (high) \\
\hline 35 & $M / 77$ & IV & + & 169 & CLB (3) & 488 & 16.7 & 5.2 & NR & $\operatorname{del}(17 p)$ & Unmutated \\
\hline 36 & $M / 55$ & IV & + & 96 & MIME (3) & 68 & 12.9 & 18.9 & $N R$ & ND & Unmutated \\
\hline 37 & $F / 64$ & IV & + & 38 & $C L B(||)$ & 27 & 65.8 & 39.9 & NR & ND & Unmutated IGHV3-2I \\
\hline
\end{tabular}

$\mathrm{CLB}=$ chlorambucil; $\mathrm{COP}=$ cyclophosphamide, vincristine, prednisone; $\mathrm{CR}=$ complete response; $\mathrm{FLUD}=$ fludarabine; $\mathrm{MIME}=$ mitoguanozone, ifosfamide, methotrexate, etoposide; $\mathrm{ND}=$ not determined; $\mathrm{NF}=$ non-functional;

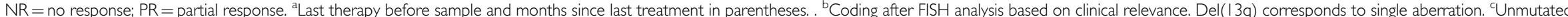

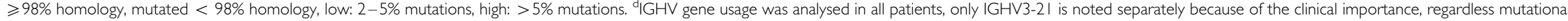
status. 
Corporation, Madison, WI, USA) protocol for adherent cells. bfl-1specific siRNA (Dharmacon SMARTpool ${ }^{\mathbb{R}}$ siRNA (proprietary target sequence)) and two nonspecific, scrambled siRNA, pooled together as 'control siRNA' were ordered from Dharmacon Research Inc. (Lafayett, CO, USA). B-CLL cells $\left(2 \times 10^{6}\right)$ suspended in $200 \mu \mathrm{l} \mathrm{AIM} \mathrm{V}$ cell culture medium supplemented with 5\% FBS, $100 \mathrm{IU} \mathrm{ml}^{-1}$ penicillin and $100 \mu \mathrm{g} \mathrm{ml}^{-1}$ streptomycin were seeded in each well in 48 -well plates. For each well $9 \mu$ l TransIT-TKO ${ }^{\mathbb{R}}$ and 80 pmol siRNA diluted in Opti-MEM ${ }^{\mathbb{R}}$ culture medium were added or cells were left untransfected. Six hours after transfection, cells were transferred to hCD40L-expressing mouse fibroblast cultures. At 24 and $48 \mathrm{~h}$ after transfection apoptotic response was determined by AnnexinV staining and mRNA expression was analysed by RT - PCR.

\section{RT - PCR}

Total RNA was isolated using RNeasy Mini Kit (Qiagen, Hilden, Germany), and reverse transcribed using N6 and oligo-(dT) $)_{18}$ primers. Thereafter, $1 \mu \mathrm{l}$ of cDNA was amplified in a $20 \mu \mathrm{l} \mathrm{PCR}$ mixture. Cycling conditions were 30 cycles of $30 \mathrm{~s}$ at $94^{\circ} \mathrm{C}, 30 \mathrm{~s}$ at $60^{\circ} \mathrm{C}$ and $30 \mathrm{~s}$ at $72^{\circ} \mathrm{C}$ for RPLP0 and 24 cycles of $1 \mathrm{~min}$ at $94^{\circ} \mathrm{C}$, $1 \mathrm{~min}$ at $60^{\circ} \mathrm{C}$ and $2 \mathrm{~min}$ at $72^{\circ} \mathrm{C}$ for bfl-1. Primers for bfl- 1 are as for competitive PCR, and for RPLP0 sense $5^{\prime}$-TTAAACCC CCTCGTGGCAATC-3'; antisense $5^{\prime}$-CCAACTTCCCCCGCATAT GA-3' (293 bp).

\section{Cytogenetic analysis}

To detect the prognostically relevant chromosomal aberrations $\operatorname{del}(13 q)$, del(11q), trisomy 12 and $\operatorname{del}(17 p)$, FISH analysis was performed using commercial probes from Abbot Vysis (Stuttgart, Germany) as described previously (Döhner et al, 2000). Twohundred interphase nuclei were analysed for each probe and sample. Samples showing between 10 and $15 \%$ cells with a particular aberration were considered as 'borderline'.

\section{IGHV gene analysis}

Genomic DNA was prepared from leukaemia cells using the QIAamp DNA Mini Kit from Qiagen (Valencia, CA, USA). PCR amplification of the IGH gene rearrangements was performed with either genomic DNA or cDNA using family-specific IGHV (framework region 1) primers together with one consensus IGHJ primer as described previously. The PCR conditions for the IGH analysis was as outlined earlier with minor modifications (Kuppers et al, 1993; Willems et al, 2000; van Dongen et al, 2003). The PCR products were either direct sequenced (35 cases) using the Big Dye Terminator Cycle Sequencing Reaction Kit (Applied Biosystems, Foster City, CA, USA) or subcloning of the PCR product (three cases) was performed using the TOPO TA Cloning Kit For Sequencing (Invitrogen, Paisley, UK). A minimum of six colonies were subsequently sequenced from each cloned sample. The sequences were analysed using an automated DNA sequencer (ABI 3700; Applied Biosystems).

The obtained IG sequences were submitted to different IG sequence databases, International ImMunoGeneTics (IMGT), IgBLAST (National Centre for Biotechnology Information, USA) and JOINSOLVER ${ }^{\circledR}$ (http://joinsolver.niams.nih.gov), and aligned to the most homologous germline IGHV, IGHD and IGHJ genes. Using the classical IGHV homology cutoff value of $98 \%$, cases were divided in unmutated ( $\geqslant 98 \%$ homology to the corresponding germline gene) or mutated ( $<98 \%$ homology) (Table 1$)$. Cases with less than $98 \%$ homology only in a non-functional rearrangement were also considered mutated. At least seven nucleotides (allowing one mutation) aligned to the most homologous germline gene were required to identify the IGHD gene segment. The mutated cases were also classified in 'low mutated' (between 97.9 and $95 \%$ of homology) or 'high mutated' ( $<95 \%$ homology). IGHV gene usage was determined in all patients and patients with IGHV3-21 usage were noted separately because of the clinical importance of this group (poor prognosis), regardless their mutational status (Tobin et al, 2002).

\section{Statistical analysis}

Estimation of statistical differences between groups was carried out using the Kruskal - Wallis test for comparison between three or more groups, and the Mann-Whitney $U$-test for comparison between two unpaired groups.

\section{RESULTS}

\section{High expression of bfl-1 correlates with chemotherapy refractoriness of $\mathrm{B}-\mathrm{CLL}$}

bfl-1 mRNA levels were determined by competitive PCR in 37 B-CLL patients, whose clinical characteristics are shown in Table 1, and correlated to in vivo response to the last chemotherapy prior to date of sampling (Figure 1A). Twenty of the 37 included patients were treated previously. Last chemotherapy and clinical responses are shown in Table 1. Expression levels of bcl-2 were also determined by competitive PCR and are shown in Figure 1B. bfl-1 expression levels were significantly higher in the NR group $($ mean $=1.77$, s.d. $=1)$ compared to the PR group (mean $=0.74$, s.d. $=0.48, P<0.05)$ and compared to the non-treated group (mean $=1.0$, s.d. $=0.89, P<0.05)$. Since most of the treated patients received CLB as the last chemotherapy, the analysis was repeated including only untreated and the 14 CLB-treated patients and equal statistic differences in bfl-1 expression were found as compared to the analysis including all the treated patients (NR vs PR $P<0.05$ and NR vs untreated $P<0.05$, data not shown). For bcl-2 there was a significant higher expression in the NR group $($ mean $=1.06$, s.d. $=0.54)$ compared to the PR group $($ mean $=0.52$, s.d. $=0.34, P<0.05)$, while the untreated group had levels in the same range as the NR group $($ mean $=1.24$, s.d. $=0.59)($ Figure $1 B)$. However, bcl-2 expression in the untreated group was significantly higher than in the PR group $(P<0.01)$. If only CLB-treated patients are included in the analysis, the difference in bcl-2 expression between NR and PR does not reach statistical significance (data not shown). High expression was seen of at least one of the genes, in a majority (10 out of 13 ) of cases in the NR group, comparing both genes together in the treated patients while the expression of both were in general low in the PR group (Figure 1C).

\section{High bfl-1 levels correlate with resistance to in vitro fludarabine-induced apoptosis}

Leukaemic cells from the patients included were tested for in vitro fludarabine- and chlorambucil-induced as well as spontaneous apoptosis. Cells were cultured in the presence or absence of drug ( $5 \mu \mathrm{M}$ fludarabine or $40 \mu \mathrm{M}$ chlorambucil) for $48 \mathrm{~h}$ and apoptosis quantified by AnnexinV staining. Specific drug-induced apoptosis was calculated after subtraction of spontaneous apoptosis as described in Materials and Methods section (Table 1). An arbitrary cutoff of $25 \%$ specific apoptosis was used to consider patient as resistant or sensitive to in vitro drug-induced apoptosis, based on our experience with in vitro cultured B-CLL cells. Fludarabineresistant cells expressed significantly higher levels of bfl-1 mRNA compared to sensitive cells $($ mean $=1.87$, s.d. $=0.99$ and mean $=0.91$, s.d. $=0.81$, respectively, $P<0.01$, Figure 2). No correlation between bfl-1 levels and spontaneous apoptosis or chlorambucil-induced apoptosis was found (data not shown). When only the untreated patients $(n=17$, Table 1) were considered, we observed that two samples were resistant to fludarabine and had very high levels of bfl-1, while samples from 

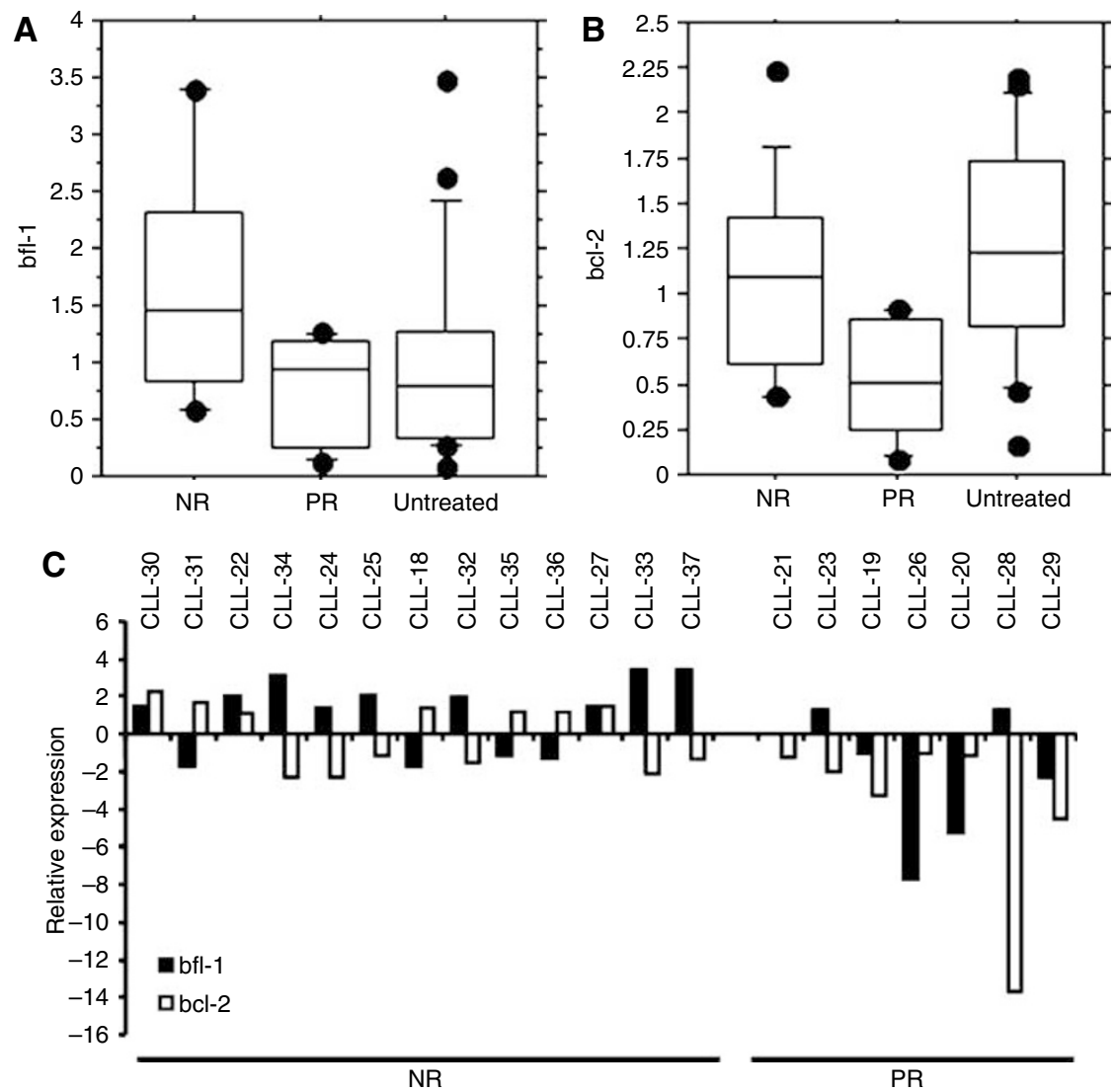

Figure I Correlation between bfl- $\mid$ and bcl-2 expression and therapy requirement and outcome bfl-I (A) and blc-2 (B) mRNA expression was determined using competitive PCR. Results are shown as mRNA expression relative to the median of the sample population. Boxes show intraquartile range. Whiskers correspond to the 10th and 90th percentile, and horizontal line within boxes represents the median value. Data correspond to 17 untreated patients, 13 patients with no response (NR) to treatment and 7 with partial response (PR). bfl-I comparison NR vs PR, $P<0.05$ and $N R$ vs untreated, $P<0.05$. bcl-2 comparison NR vs PR, $P<0.05$ and $P R$ vs untreated, $P<0.01$. (C) Comparison of bfl- $I$ and bcl- 2 mRNA expression, as determined by competitive PCR, and therapy outcome. Data are represented as fold increase/decrease mRNA expression relative to the median of the sample population.

the rest of the untreated patients were sensitive and expressed low levels of bfl-1 mRNA $(P<0.05$, data not shown). There was no significant correlation between bfl-1 expression and apoptotic response to fludarabine in the treated group (data not shown). No difference in expression of bcl-2 mRNA was detected between cells that were either sensitive or resistant to fludarabine or chlorambucil treatment in vitro (data not shown). Cells from NR patients were significantly more resistant to fludarabine than those from PR or untreated patients $(P<0.01)$ (data not shown).

\section{Relationship between bfl-1 expression and disease progression, IGHV mutational status and genetic alterations}

Next, we wanted to investigate if bfl-1 was involved in disease progression, and thus bfl-1 mRNA expression was compared between progressive and non-progressive patients. Although there was a tendency to higher bfl-1 expression in progressive patients the difference did not achieve statistical significance (data not shown). In addition, bfl-1 expression did not correlate with lymphocyte count, Rai stage, age, sex or CD38 expression (data not shown).

The IGHV gene mutation status was analysed in 36 B-CLL cases included in this study using IGHV gene family-specific PCR amplification and nucleotide sequencing as described in Materials and Methods section (Table 1 ). bfl-1 or bcl-2 mRNA expression did not correlate with the mutational status of the patients, independently of cutoff value (98 or $95 \%$ ) and if the five cases using the VH3-21 gene were considered as a separated group (data not shown).

The prognostically relevant chromosomal aberrations del(11q), trisomy $12, \operatorname{del}(13 q)$ and $\operatorname{del}(17 p)$ were analysed by fluorescence in situ hybridisation (FISH) in 28 B-CLL cases. We found three B-CLL patients with no aberration (11) and 11 (39\%) with the good prognostic aberration $13 \mathrm{q}$ deletion as single aberration, whereas the intermediate prognostic aberration trisomy 12 and the poor prognostic aberrations $11 \mathrm{q}$ deletion and $17 \mathrm{p}$ deletion were detected in 4 (14), 5 (18) and 4 (14\%) patients, respectively. Among the patients with $17 \mathrm{p}$ deletion one was considered borderline $(10-15 \%$ cells with the aberration). In one patient $(3 \%)$, the FISH data were not conclusive (Table 1). bfl-1 or bcl-2 mRNA was significantly higher expressed in the good prognosis del(13q)/ 'normal' group as compared to the intermediate/bad prognosis trisomy $12 / \mathrm{del}(11 \mathrm{q}) / \mathrm{del}(17 \mathrm{p})$ group $(P<0.01$ and $P<0.02$, respectively) (Figure 3 ). bfl-1 or bcl-2 mRNA expression was also compared, within each cytogenetic group (good and intermediate/ bad prognosis), between NR and PR patients, and between treated and untreated patients. Although this study included too few patients to make a proper analysis and draw any conclusions, we noted that both bfl-1 and bcl-2 levels were higher in NR patients than in PR patients, independent of the cytogenetic status. However, there were no differences between treated and untreated patients within each cytogenetic group (data not shown). 


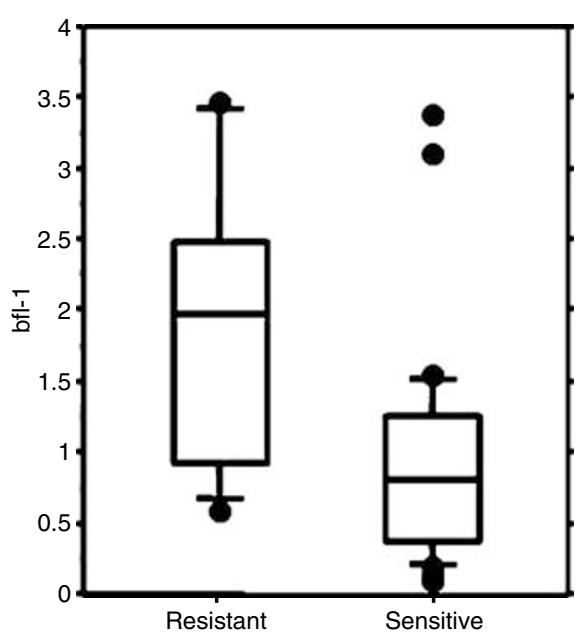

Figure 2 Correlation between bfl- $\mid$ expression and in vitro fludarabineinduced apoptosis. Isolated B cells $\left(0.5 \times 10^{6}\right)$ from B-CLL patients (all 37 patients included in the study, Table I) were cultured in 96-well plates in medium alone (non-supplemented with FBS) or with fludarabine $(5 \mu \mathrm{M})$. Apoptosis was measured after $48 \mathrm{~h}$ of culture using AnnexinV staining and fludarabine-specific apoptosis was calculated as described in Materials and Methods section. Cells were considered resistant if specific fludarabineinduced apoptosis was less than $25 \%$ (resistant, $n=11$; sensitive, $n=26$ ). bfl- I mRNA expression was determined before culture using competitive PCR. Results are shown as mRNA expression relative to the median of the sample population. Boxes show intraquartile range. Whiskers correspond to the I0th and 90th percentile, and horizontal line within boxes represents the median value. Comparison: resistant vs sensitive, $P<0.0$ I.

\section{siRNA-mediated downregulation of bfl-1 induces apoptosis in resistant B-CLL cells}

To test directly the contribution of blf- 1 to apoptosis resistance in B-CLL we targeted bfl-1 expression by specific siRNA in fludarabine-resistant, bfl-1 high-expressing B-CLL cells (CLL-24, CLL-32, CLL-27 and CLL-33; Figure 4). Initial experiments with fluorescently labelled nonspecific siRNA showed efficient uptake in B-CLL cells under the conditions used (Derkow, unpublished observation). Downmodulation of bfl-1 mRNA was seen $24 \mathrm{~h}$ after transfection (Figure 4A) and expression levels did not decrease further at $48 \mathrm{~h}$ (not shown). At $24 \mathrm{~h}$ apoptosis was also clearly induced in cells transfected with bfl-1-specific siRNA but not in cells transfected with control siRNA or in untransfected cells (Figure 4B) and did only further increase slightly at $48 \mathrm{~h}$ (not shown), showing that in these resistant cases with high bfl-1 expression, bfl-1 is indeed important for the survival of the cells.

\section{DISCUSSION}

Even though the majority of symptomatic B-CLL patients respond to initial therapy, almost all progress and develop refractory disease given sufficient time. The underlying defects in apoptosis in B-CLL cells presumably contribute to the chemotherapy resistance in such patients. Here, we have shown high bfl-1 mRNA expression in leukaemic cells from chemotherapy refractory B-CLL patients. Several members of the Bcl-2 family of apoptosisregulating proteins have previously been implicated in the deregulation of apoptosis and in chemotherapy resistance in B-CLL (Morales et al, 2005). Higher levels of Mcl-1 have been reported to be associated with a failure to achieve complete remission following chemotherapy (Kitada et al, 1998). Higher levels of Bcl-2 protein or higher Bcl-2/Bax ratios have been associated with in vitro resistance to drug-induced apoptosis (McConkey et al, 1996; Thomas et al, 1996). Increased Bcl-2/Bax

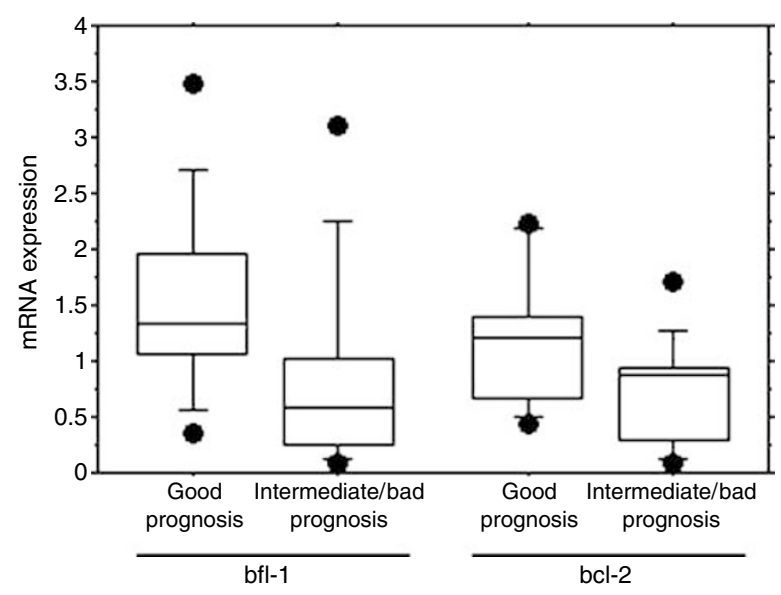

Figure 3 Correlation between bfl-l and bcl-2 expression and chromosomal aberrations. The prognostically relevant chromosomal aberrations $\operatorname{del}(\mid 3 q)$, trisomy 12 , $\operatorname{del}(|| q)$ and $\operatorname{del}(\mid 7 p)$ were determined by FISH analysis in $28 \mathrm{~B}-\mathrm{CLL}$ patients included in the study (Table I). Patients were grouped in good prognosis del(13q)/'normal' group $(n=14)$ and intermediate/bad prognosis trisomy $\mid 2 / \mathrm{del}(\mathrm{I} \mid \mathrm{q}) / \mathrm{del}(\mathrm{I} / \mathrm{p})$ group $(n=13)$. bfl-l and blc-2 mRNA expression was determined using competitive PCR and results are shown as mRNA expression relative to the median of the sample population. Boxes show intraquartile range. Whiskers correspond to the 10th and 90th percentile, and horizontal line within boxes represents the median value. Comparison $\operatorname{del}(\mid 3 q) /{ }^{\prime}$ normal' vs trisomy $12 / \mathrm{del}(\mid \mathrm{|q}) / \mathrm{del}(\mid 7 p)$ for bfl-,$P<0.01$, and for $b c l-2 P<0.02$.

ratios have also been correlated to a more aggressive behaviour of B-CLL, including progressive disease, refractoriness to chemotherapy, and shorter survival (Aguilar-Santelises et al, 1996, Pepper et al, 1998). However, not all studies have identified an association between $\mathrm{Bcl}-2$ or Bax expression and chemoresistance and/or clinical outcome in B-CLL, implying that other factors play a role (Robertson et al, 1996; Johnston et al, 1997; Kitada et al, 1998). Using microarrays, we recently found a pattern of high expression levels of bfl-1, bcl-2 and mcl-1 mRNAs in apoptosisresistant B-CLL cells (Morales et al, 2005). In our current study, we found significantly higher expression of bfl-1 and bcl-2 in the refractory patients. The strongest difference between nonresponding and responding patients was seen when both bfl-1 and bcl-2 were considered together, with high expression of at least one of the genes in the refractory group compared to low expression of both in patients that had responded to chemotherapy. This indicates that the expression of both bfl-1 and bcl-2, and possibly additional members of the bcl-2 family, such as mcl-1, may give the best prediction of chemotherapy response.

Our current results do not answer if high mRNA expression levels of bfl-1 is predictive of chemotherapy outcome or if it is a result of resistance development. The fact that most untreated patients had low bfl-1 levels and that the majority of the treated patients had received several rounds of treatment, responding initially, argues that bfl-1 expression could be increased as a result of treatment and might contribute to resistance development. In fact, bfl-1 has previously been implicated in chemotherapy resistance development in model systems. Increased expression of bfl-1 has been found in an in vivo established vinflunineresistant murine leukaemia cell line as well as in in vitro established cisplatin-resistant bladder cancer cell lines compared to their respective sensitive parental cell lines (Kruczynski et al, 2002; Kim et al, 2004). We have found that fludarabine did not induce increased bfl-1 expression in B-CLL cells in a short-term culture (Olsson, unpublished observation). However, most patients had been receiving other chemotherapy regimens and the increased bfl-1 expression could be a long-term effect or due to 

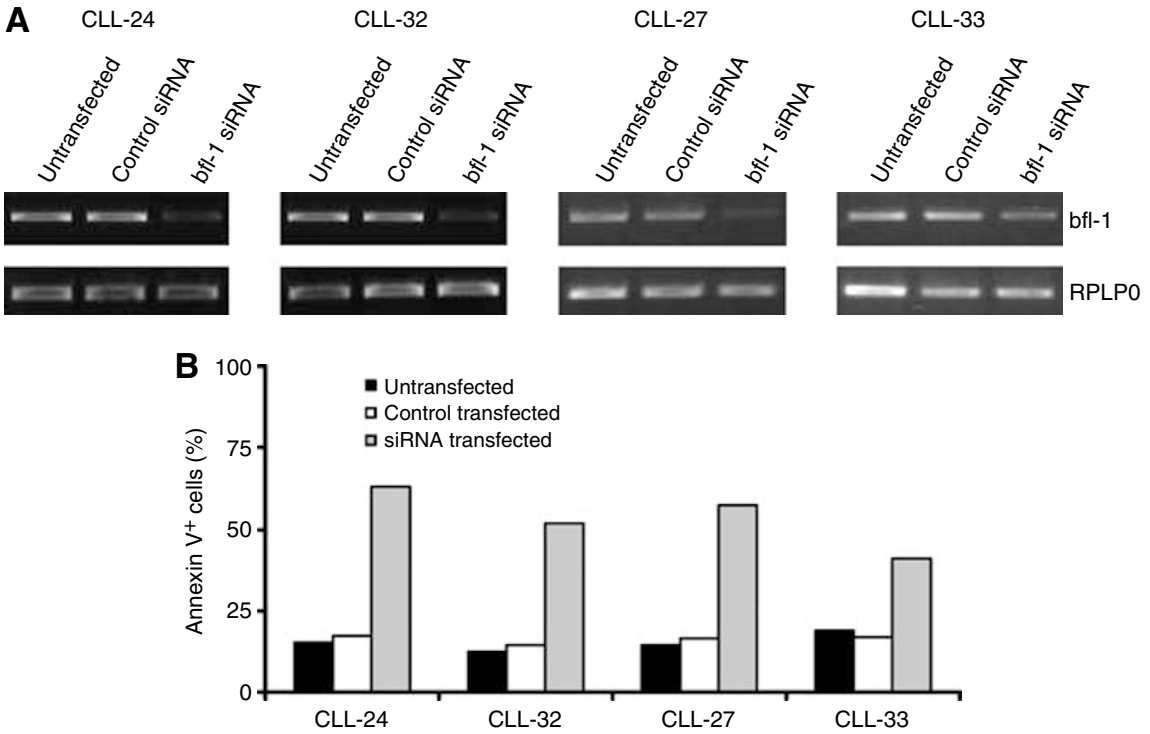

Figure 4 siRNA-mediated targeting of bfl-I in B-CLL cells. B-CLL cells from four in vitro fludarabine-resistant and bfl-I high-expressing cases (CLL-24, CLL-32, CLL-27 and CLL-33) were transfected with bfl- I-specific siRNA, control siRNA oligo or were not transfected. At $24 \mathrm{~h}$ cells were harvested, mRNA was isolated and analysed for bfl-I mRNA expression by RT-PCR. (A) At the same time apoptosis was quantified using AnnexinV staining to quantify apoptosis. (B) Data show one representative experiment out of two.

selective killing of cells expressing lower levels of bfl-1. Prospective studies are warranted to resolve this question.

We did not find any correlation between high expression of bfl-1 and progressive disease or advanced stage of disease. This indicates that at least in part different factors govern disease progression/aggressiveness of disease and chemotherapy refractoriness. Absence of somatic IGHV hypermutations has been associated with the requirement of therapy and poor survival (Damle et al, 1999; Hamblin et al, 1999). Although no study investigating the impact of IGHV mutation status on the outcome of therapy of B-CLL patients has been reported, an in vitro study shows higher sensitivity to induction of apoptosis by several chemotherapeutic agents in unmutated cases (Aleskog et al, 2004). This, together with our results of no correlation of bfl-1 or bcl-2 antiapoptotic gene expression with the mutational status, suggest that the difference in prognosis between B-CLL cases with unmutated or mutated IGHV genes is not explained by the cellular apoptosis sensitivity.

It was surprising to find a higher expression of bfl-1 mRNA in patients with $\operatorname{del}(13 q)$ or 'normal' karyotype, as compared to the trisomy 12/del(11q)/del(17p) group. As a single cytogenetic defect, $\operatorname{del}(13 q)$ is a good prognosis marker, associated with longer overall and treatment-free interval (Döhner et al, 2000). However, there is no study on the prognostic significance of $\operatorname{del}(13 \mathrm{q})$ on the response to therapy. Others have found higher bcl-2 expression in B-CLL cells with del(13q) or normal karyotype as compared to the bad prognosis groups del(17p), trisomy 12 or $\operatorname{del}(11 q)$, which is in agreement with our results (Jahrsdörfer et al, 2005). In addition, the expression of two microRNAs, miR-15a and miR-16-1, is inversely correlated to bcl-2 expression in B-CLL samples and they negatively regulate bcl-2 at a post-transcriptional level (Cimmino et al, 2005). These two microRNAs are located in the minimally deleted region at 13q14.3, which could explain the high expression of bcl-2 in the del(13q) group. Further studies are ongoing to explore the relation between chromosomal aberrations and apoptosis-regulating genes in B-CLL, as well as to determine the predictive value of apoptosis-regulating genes for the treatment response in good and bad prognosis cytogenetic groups.

We found a correlation between bfl-1 expression and in vitro fludarabine-induced apoptosis, but not with spontaneous or chlorambucil-induced apoptosis. However, bfl-1 expression correlated with in vivo response to chlorambucil. Previously, Mcl-1 expression was reported to correlate to in vitro chlorambucilinduced apoptosis but not to fludarabine-induced apoptosis (Johnston et al, 2004). Although both drugs induce apoptosis through a mitochondria-dependent pathway, initiation of the pathway may depend on different mechanisms, which might be selectively counteracted by bfl-1 or mcl-1. In contrast to what is the case for the proapoptotic bcl-2 family members, not much is known about functional differences between individual antiapoptotic members of the family. Growing evidence indicates, however, that different antiapoptotic bcl-2 family members are counteracted specifically by different proapoptotic BH3-only proteins activated by different signals (Chen et al, 2005; Willis et al, 2005). Further studies are bound to find other functional niches for other antiapoptotic bcl-2 members, which might explain their selective protection against various apoptotic stimuli activating the mitochondrial pathway. Our contradictory results regarding the correlation of bfl-1 expression level with in vitro and in vivo response to chlorambucil might also be explained by differences in the mechanisms regulating the apoptotic process in vitro and in vivo.

By selectively downmodulating bfl-1 using specific siRNA we could induce apoptosis in fludarabine-resistant B-CLL cells, showing that bfl-1 has a protective role against apoptosis in these cells. Together with our recent finding that bfl-1 mRNA expression levels are decreased in apoptosis-sensitive cells during spontaneous apoptosis in vitro (Morales et al, 2005) and the finding by Kater et al (2004) that CD40L, known to promote survival of B-CLL cells in vivo, induces the expression of bfl-1 in B-CLL cells, protecting them from spontaneous and fludarabine-induced apoptosis in vitro, this finding suggests that bfl-1 may be important for the extended survival of the leukaemic cells in vivo.

Targeting bcl-2 family members is recognised as a promising therapeutic strategy in B-CLL. bcl-2 antisense therapeutic strategy has proven feasible without toxicity and is already in clinical trials for B-CLL patients (O'Brien et al, 2005). Our results suggest that an approach involving also the targeting of bfl-1 deserves further testing. 


\section{REFERENCES}

Aguilar-Santelises M, Rottenberg ME, Lewin N, Mellstedt H, Jondal M (1996) Bcl-2, Bax and p53 expression in B-CLL in relation to in vitro survival and clinical progression. Int J Cancer 69: 114-119

Åleskog A, Tobin G, Laurell A, Thunberg U, Lindhagen E, Roos G, Nilsson K, Nygren P, Sundstrom C, Hoglund M, Larsson R, Rosenquist R (2004) $\mathrm{VH}$ gene mutation status and cellular drug resistance in chronic lymphocytic leukaemia. Eur J Haematol 73: 407-411

Bernal A, Pastore RD, Asgary Z, Keller SA, Cesarman E, Liou HC, Schattner EJ (2001) Survival of leukemic B cells promoted by engagement of the antigen receptor. Blood 98: $3050-3057$

Chen L, Willis SN, Wei A, Smith BJ, Fletcher JI, Hinds MG, Colman PM, Day CL, Adams JM, Huang DCS (2005) Differential targeting of prosurvival $\mathrm{Bcl}-2$ proteins by their $\mathrm{BH} 3$-only ligands allows complementary apoptotic function. Mol Cell 17: 393-403

Cheson BD, Bennet JM, Grevre M, Kay N, Keating MJ, O'Brien S, Rai KR (1996) National Cancer Institute-sponsored working group guidelines for chronic lymphocytic leukemia: revised guidelines for diagnosis and treatment. Blood 87: 4990-4997

Cimmino A, Calin GA, Fabbri M, Iorio MV, Ferracin M, Shimizu M, Wojcik SE, Aqeilan RI, Zupo S, Dono M, Rassenti L, Alder H, Volinia S, Liu C, Kipps TJ, Negrini M, Croce CM (2005) miR-15 and miR-16 induce apoptosis by targeting BCL2. PNAS 102: 13944-13949

Craxton A, Chuang PI, Shu G, Harlan JM, Clark EA (2000) The CD40inducible $\mathrm{Bcl}-2$ family member $\mathrm{A} 1$ protects $\mathrm{B}$ cells form antigen receptormediated apoptosis. Cell Immunol 200: 56-62

Damle RN, Wasil T, Fais F, Ghiotto F, Valetto A, Allen SL, Buchbinder A, Budman D, Dittmar K, Kolitz J, Lichtman SM, Schulman P, Vinciguerra VP, Rai KR, Ferrarini M, Chiorazzi N (1999) IgVH gene mutation status and CD38 expression as novel prognostic indicators in chronic lymphocytic leukemia. Blood 94: 1840-1847

Döhner H, Stilgenbauer S, Benner A, Leupolt E, Kröber A, Bullinger L, Döhner K, Bentz M, Lichter P (2000) Genomic aberrations and survival in chronic lymphocytic leukemia. N Engl J Med 343: 1910-1916

D'Sa-Eipper C, Subramanian T, Chinnadurai G (1996) bfl-1, a bcl-2 homologue, suppresses p53-induced apoptosis and exhibits potent cooperative transforming activity. Cancer Res 56: 3879-3882

Hamblin TJ, Oscier DG (1997) Chronic lymphocytic leukaemia: the nature of the leukaemic cell. Blood Rev 11: 71-73

Hamblin TJ, Davis Z, Gardiner A, Oscier DG, Stevenson FK (1999) Unmutated $\mathrm{Ig} \mathrm{V}_{\mathrm{H}}$ genes are associated with a more aggressive form of chronic lymphocytic leukemia. Blood 94: 1848-1854

Horie R, Watanable M, Okamura T, Taira M, Shoda M, Motoji T, Utsunomiya A, Watanable T, Higashihara M, Umezawa K (2006) DHMEQ, a new NF- $\kappa$ B inhibitor, induces apoptosis and enhances fludarabine effects on chronic lymphocytic leukaemia cells. Leukemia 20: $800-806$

Jahrsdörfer B, Wooldridge JE, Blackwell SE, Taylor CM, Link BK, Weiner GJ (2005) Good prognosis cytogenetics in B-cell chronic lymphocytic leukaemia is associated in vitro with low susceptibility to apoptosis and enhanced immunogenicity. Leukaemia 19: 759-766

Johnston JB, Daeninck P, Verburg L, Lee K, Williams G, Israels LG, Mowat MR, Begleiter A (1997) P53, MDM-2, BAX and BCL-2 and drug resistance in chronic lymphocytic leukemia. Leuk Lymphoma 26: 349-435

Johnston JB, Paul JT, Neufeld NJ, Haney N, Kropp DM, Hu X, Cheang M, Gibson SB (2004) Role of myeloid cell factor-1 (Mcl-1) in chronic lymphocytic leukemia. Leuk Lymphoma 45: 2017 - 2027

Jung-Ha H, Kim D, Lee SB, Hong SI, Park SY, Huh J, Kim CW, Kim SS, Lee Y, Choi SS, Shin HS (1998) Expression of Bfl-1 in normal and tumor tissues: Bfl-1 overexpression in cancer is attributable to its preferential expression in infiltrating inflammatory cells. Hum Pathol 29: $723-728$

Jurlander J (1997) The cellular biology of B-cell chronic lymphocytic leukemia. Crit Rev Onc Hematol 27: 29-52

Karsan A, Yee E, Kaushansky K, Harlan JM (1996) Cloning of human Bcl-2 homologue: inflammatory cytokines induce human A1 in cultured endothelial cells. Blood 87: $3089-3096$

Kater AP, Evers LM, Remmerswaal EB, Jaspers A, Oosterwijk MF, van Lier RA, van Oers MH, Eldering E (2004) CD40 stimulation of B-cell chronic lymphocytic leukaemia cells enhances the anti-apoptotic profile, but also Bid expression and cells remain susceptible to autologous cytotoxic T-lymphocyte attack. Br J Haematol 127: 404-415

Kim JK, Kim KD, Lee E, Lim JS, Cho HJ, Yoon HK, Cho MY, Baek KE, Park YP, Paik SG, Choe YK, Lee HG (2004) Up-regulation of Bfl-1/A1 via
NF-kappaB activation in cisplatin-resistant human bladder cancer cell line. Cancer Lett 212: $61-70$

Kitada S, Andersen J, Akar S, Zapata JM, Takayama S, Krajewski S, Wang HG, Zhang X, Bullrich F, Croce CM, Rai K, Hines J, Reed JC (1998) Expression of apoptosis-regulating proteins in chronic lymphocytic leukemia: correlations with in vivo and in vitro chemoresponses. Blood 91: $3379-3389$

Kruczynski A, Etiévant C, Perrin D, Chansard N, Duflos A, Hill BT (2002) Characterization of cell death induced by vinflunine, the most recent Vinca alkaloid in clinical development. Br J Cancer 86: 143-150

Kucharczak JF, Simmons MJ, Duckett CS, Gelinas C (2005) Constitutive proteasome-mediated turnover of $\mathrm{Bfl}-1 / \mathrm{Al}$ and its processing in response to TNF receptor activation in FL5.12 pro-B cells convert it into a prodeath factor. Cell Death Differ 12: 1225 - 1239

Kuppers R, Zhao M, Rajevsky K, Hansmann ML (1993) Detection of clonal $\mathrm{B}$ cell population in paraffin-embedded tissues by polymerase chain reaction. Am J Pathol 143: 230-239

Kuss AW, Knodel M, Berberich-Siebelt F, Lindemann D, Schimpl A, Berberich I (1999) A1 expression is stimulated by CD40 in B cells and rescues WEHI 231 cells from anti-IgM-induced cell death. Eur J Immunol 29: $3077-3088$

McConkey DJ, Chandra J, Wright S, Plunkett W, McDonnell TJ, Reed JC, Keating M (1996) Apoptosis sensitivity in chronic lymphocytic leukemia is determined by endogenous endonuclease content and relative expression of BCL-2 and BAX. J Immunol 156: 2624-2630

Morales AA, Olsson A, Celsing F, sterborg A, Jondal M, Osorio LM (2005) High expression of bfl-1 contributes to the apoptosis resistant phenotype in B-cell chronic lymphocytic leukemia. Int J Cancer 113: 730-737

Moreb JS, Schweder M (1997) Human A1, a bcl-2-related gene, is induced in leukemic cells by cytokines as well as differentiating factors. Leukemia 11: $998-1004$

O’Brien SM, Cunningham CC, Golenkov AK, Turkina AG, Novick SC, Rai KR (2005) Phase I to II multicenter study of Oblimersen Sodium, a Bcl-2 antisense oligonucleotide, in patients with advanced chronic lymphocytic leukaemia. J Clin Oncol 23: 7697-7702

O'Brien S, del Giglio A, Keating M (1995) Advances in the biology and treatment of B-cell chronic lymphocytic leukemia. Blood 85: $307-318$

Osorio LM, De Santiago A, Aguilar-Santelises M, Mellstedt H, Jondal M (1997) CD6 ligation modulates the Bcl-2/Bax ratio and protects chronic lymphocytic leukemia B cells from apoptosis induced by anti-IgM. Blood 89: $2833-2841$

Pepper C, Hoy T, Bentley P (1998) Elevated Bcl-2/Bax are consistent feature of apoptosis resistance in B-cell chronic lymphocytic leukemia and are correlated with in vivo chemoresistance. Leuk Lymphoma $\mathbf{2 8}$ $355-361$

Rai KR, Sawitsky A, Cronkite EP, Chanana AD, Levy RN, Pasternack BS (1975) Clinical staging of chronic lymphocytic leukemia. Blood 46: $219-234$

Robertson LE, Plunkett W, McConnell K, Keating MJ, McDonnell TJ (1996) Bcl-2 expression in chronic lymphocytic leukemia and its correlation with the induction of apoptosis and clinical outcome. Leukemia 10: $456-459$

Silver RT, Sawitsky A, Rai K, Holland JF, Glidewell O (1978) Guidelines for protocol studies in chronic lymphocytic leukemia. Am J Hematol 4: $343-358$

Thomas A, El Rouby S, Reed JC, Krajewski S, Silber R, Potmesil M, Newcomb EW (1996) Drug-induced apoptosis in B-cell chronic lymphocytic leukemia: relationship between p53 gene mutation and bcl-2/bax proteins in drug resistance. Oncogene 12: $1055-1062$

Tobin G, Thunberg U, Johnson A, Thorn I, Söderberg O, Hultdin M, Botling J, Enblad G, Sällström J, Sundström C, Roos G, Rosenquist R (2002) Somatically mutated $\mathrm{Ig} \mathrm{V}_{\mathrm{H}}$ 3-21 genes characterize a new subset of chronic lymphocytic leukemia. Blood 99: 2262-2264

van Dongen JJM, Langerak AW, Bruggemann M, Evans PA, Hummel M, Lavender FL, Delabesse E, David F, Schuuring E, Garcia-Sanz R, van Krieken JH, Droese J, Gonzalez D, Bastard C, White HE, Spaargaren M, Gonzalez M, Parreira A, Smith JL, Morgan GJ, Kneba M, Macintyre EA (2003) Design and standardization of PCR primers and protocols for detection of clonal immunoglobulin and T-cell receptor gene recombinations in suspect lymphoproliferations: Report of the BIOMED-2 Concerted Action BMH4-CT98-3936. Leukemia 17: $2257-2317$ 
Wang CY, Guttridge DC, Mayo MW, Baldwin Jr AS (1999) NF- $\kappa$ B induces expression of the Bcl-2 homologue A1/Bfl-1 to preferentially suppress chemotherapy-induced apoptosis. Mol Cell Biol 19: 5923-5929

Werner AB, de Vries E, Tait SW, Bontjer I, Borst J (2002) Bcl-2 family member Bfl-1/A1 sequesters truncated bid to inhibit is collaboration with pro-apoptotic Bak or Bax. J Biol Chem 277: 22781 - 22788

Willems P, Verhagen O, Segeren C, Veenhuizen P, Guikema J, Wiemer E, Groothuis L, Buitenweg-de Jong T, Kok H, Bloem A, Bos N, Vellenga E, Mensink E, Sonneveld P, Lokhorst H, van der Schoot E, Raymakers R (2000) Consensus strategy to quantitate malignant cells in myeloma patients is validated in a multicenter study. Blood 96: 63-70
Willis SN, Chen L, Dewson G, Wei A, Naik E, Fletcher JI, Adams JM, Huang DCS (2005) Proapoptotic bak is sequestered by Mcl-1 and Bcl-xL, but not Bcl-2, until displaced by BH3-only proteins. Genes Dev 19: $1294-1305$

Zhang H, Cowan-Jacob SW, Simonen M, Greenhalf W, Heim J, Meyhack B (2000) Structural basis of BFL-1 for its interaction with BAX and its anti-apoptotic action in mammalian and yeast cells. J Biol Chem 275: $11092-11099$

Zong WX, Edelstein LC, Chen C, Bash J, Gélinas C (1999) The prosurvival $\mathrm{Bcl}-2$ homolog Bfl-1/A1 is a direct transcriptional target of $\mathrm{NF} \kappa \mathrm{B}$ that blocks TNF $\alpha$-induced apoptosis. Genes Dev 13: $382-387$ 